\title{
Removal of As(V) Based on Amino-Group Surface-Functionalized Porous Silicon Derived from Photovoltaic Silicon Cutting Powder
}

\author{
Kaixin Fu ${ }^{1}$, Yi Li ${ }^{1}$, Xiumin Chen ${ }^{2}$, Wenhui Ma ${ }^{2}$, Ziheng Yang ${ }^{1}$, Tong Wang ${ }^{2}$, Jiasen Liu ${ }^{1}, Z_{\text {huang Ma }}{ }^{1}$, \\ Ran Chen ${ }^{3}$, Xiuhua Chen ${ }^{1,4, *}$ and Shaoyuan $\mathrm{Li}^{2, *}$
}

1 School of Materials and Energy, Yunnan University, Kunming 650091, China; fkaixin@mail.ynu.edu.cn (K.F.); innovator777@126.com (Y.L.); 18213057158@163.com (Z.Y.); liujasen@163.com (J.L.); 15827016731@163.com (Z.M.)

2 Faculty of Metallurgical and Energy Engineering/State Key Laboratory of Complex Nonferrous Metal Resources Clean Utilization, Kunming University of Science and Technology, Kunming 650093, China; chenxiumin9@outlook.com (X.C.); mwhsilicom@126.com (W.M.); wtsilicon@msn.cn (T.W.)

3 Australian Centre for Advanced Photovoltaics, School of Photovoltaic and Renewable Energy Engineering, University of New South Wales, Sydney, NSW 2052, Australia; ran.chen@unsw.edu.au

4 Nature Center for International Research on Photoelectric and Energy Materials, Yunnan University, Kunming 650091, China

* Correspondence: chenxh@ynu.edu.cn (X.C.); 1sy415808550@163.com (S.L.)

\section{check for} updates

Citation: Fu, K.; Li, Y.; Chen, X.; Ma, W.; Yang, Z.; Wang, T.; Liu, J.; Ma, Z.; Chen, R.; Chen, X.; et al. Removal of As(V) Based on Amino-Group Surface-Functionalized Porous Silicon Derived from Photovoltaic Silicon Cutting Powder. Coatings 2021, 11, 850. https://doi.org/10.3390/ coatings 11070850

Academic Editor:

Tadeusz Hryniewicz

Received: 16 June 2021

Accepted: 9 July 2021

Published: 15 July 2021

Publisher's Note: MDPI stays neutral with regard to jurisdictional claims in published maps and institutional affiliations.

Copyright: (c) 2021 by the authors. Licensee MDPI, Basel, Switzerland. This article is an open access article distributed under the terms and conditions of the Creative Commons Attribution (CC BY) license (https:// creativecommons.org/licenses/by/ $4.0 /)$
Abstract: In this study, amino group surface-functionalized porous silicon adsorbent was successfully prepared for the first time using diamond wire saw silicon powder (DWSSP) as raw material through copper-assisted chemical etching $(\mathrm{Cu}-\mathrm{ACE})$ and organic functional group grafting. Aminofunctionalized porous silicon adsorbent (TEPA-GTS-NPSi) can be used for removing $\mathrm{As}(\mathrm{V})$ from water. The properties and mechanism of the new adsorbent were characterized by infrared spectroscopy (FT-IR), X-ray photoelectron spectroscopy (XPS), scanning electron microscopy (FE-SEM), Brunauer-Emmett-Teller analysis (BET), and thermogravimetric analysis (TGA). The concentration of metal ions in the solution was determined by inductively coupled plasma spectrometry. Meanwhile, the effects of initial $\mathrm{pH}$, adsorption time, initial concentration and adsorbent dosage on the removal of $\mathrm{As}(\mathrm{V})$ in an aqueous solution were studied by intermittent adsorption experiments. The results showed that the adsorption equilibrium could be reached rapidly after 30 min soaking. Under the optimized $\mathrm{pH}$ of 7, the maximum adsorption capacity was $13.2 \mathrm{mg} / \mathrm{g}$, and the minimum adsorption limit was $3 \mathrm{mg} / \mathrm{L}$. The adsorbent shows good adsorption performance after five successive regenerated cycles. Based on the density functional theory (DFT) analysis results, the adsorption mechanism is attributed to hydrogen bond interaction between the $\mathrm{NH}_{2}$ group and $\mathrm{As}(\mathrm{V})$ ions.

Keywords: silicon cutting powder; copper-assisted chemical etching; surface modification; waste recycling; arsenic removal

\section{Introduction}

Solar energy has become one of the most important clean energy sources in recent years. As we know, the silicon solar cell, one of the most important photovoltaic devices, is widely acclaimed for its advantages, such as easy installation, low maintenance cost and strong adaptability [1]. As a result, silicon ingots are the main raw material of the solar energy industry [2]. Metallurgical grade silicon (MG-Si, $<99 \%, 2 \mathrm{~N}$ ) is purified into solar grade silicon ( $\mathrm{SoG}-\mathrm{Si},>99.9999 \%, 6 \mathrm{~N}$ ) ingots by a high consumption process. During the slicing process, about $35 \%$ of the silicon ingot becomes cutting silicon powder [3]. With the innovations in slicing technology, however, it is roughly estimated that more than 160,000 tons of diamond wire saw silicon powder (DWSSP) will be discarded in 2019 alone, as shown in Figure S1. If a large amount of micron and sub-micron cutting powder is 
directly discharged, it will not only cause the waste of resources but also further increase pollution of the environment. Therefore, the value-added recovery of cutting waste will bring considerable environmental and economic benefits [4-6].

Arsenic is widely found in nature, and arsenic pollution mainly comes from the exploitation, smelting and extensive use of arsenic compounds, such as the production and use of arsenic-containing pesticides, and many industries, all of which led to arsenic contamination in the environment [7]. If the human body is chronically exposed to arsenic, it can lead to a range of chronic diseases and cancer [8]. The abundant existing species of arsenic in pollutants are inorganic and organic arsenic, and the toxicity of the inorganic form is worse than that of the organic form. The main existing forms of inorganic arsenic are $\mathrm{As}(\mathrm{III})$ and $\mathrm{As}(\mathrm{V})$. In the process of treating wastewater polluted by arsenic, the oxidation of $\mathrm{As}(\mathrm{III})$ into $\mathrm{As}(\mathrm{V})$ is mostly adopted for subsequent treatment [9]. To date, diverse treatment technologies, such as chemical precipitation [10], ion exchange [11] and electrocoagulation [12], as well as ultrafiltration (UF) [13], nanofiltration (NF) and reverse osmosis (RO) [14], have been used for removal of arsenic. However, these technologies have disadvantages, such as high energy costs and excessive use of toxic substances, and they can also easily cause secondary pollution; hence, they have certain limitations in practical applications. Adsorption technology has been widely studied because of its advantages of high efficiency, flexibility, and simple operation [15-17]. Therefore, this is an environmentally friendly method for removing high concentrations of arsenic. Among various adsorbents, silica gel or magnetic nanoparticles were used as the substrate and modified by organic functional groups as adsorbents of arsenic $[18,19]$. Porous silicon can be used for modification of organic functional molecules due to its large specific surface area and more active groups ( $\mathrm{Si}-\mathrm{OH}$ ) on the surface [20-22], which can also be used as a potential adsorbent substrate material. According to a research report by Dariusz M. Jarzabek, et al., the friction performance of the silicon surface was greatly improved when the porous silicon was exposed to an aqueous solution of alkali metal ions [23]. On the other hand, the organic modification of the hydrogen-terminated silicon surface summarized by Danial D. M. Wayner et al. also provides more possibilities for the application of modified porous silicon [24].

Herein, we focus on the resource recycling and the removal of arsenic in aqueous solution based on porous silicon derived from the DWSSP combined with copper nanoparticleassisted chemical etching [21,22], and modification of 3-GTS and TEPA. The effects of initial $\mathrm{pH}$ value, initial concentration of $\mathrm{As}(\mathrm{V})$, contact time and amount of adsorbent on the adsorption property of the resulting organic-inorganic hybrid were carefully investigated. Moreover, the uptake performance for arsenic of TEPA-GTS-NPSi was appraised by isothermal adsorption, thermodynamics, and kinetics studies. To further clarify the arsenic adsorption process, the experimental data of kinetics were fitted by using a pseudo-firstorder model and a pseudo-second-order model. Finally, the adsorption mechanism was further confirmed by DFT analysis. This work not only solves the problem of silicon waste recovery in the photovoltaic industry but also provides a potentially feasible strategy for $\mathrm{As}(\mathrm{V})$ adsorption in aqueous solution.

\section{Materials and Methods}

\subsection{Chemicals and Reagent}

Diamond-wire saw cutting silicon powder was provided by LONGi Silicon Material Co. Ltd. (Chuxiong, China). (3-glycidyloxypropyl) trimethoxy-silane (3-GTS, 99.9\%) and tetraethylenepentamine (TEPA, 99.9\%) were purchased from the Aladdin Chemistry Co. Ltd., Shanghai, China. Arsenic stock solution (1000 mg/L) was purchased from the National Research Center for Standard Materials (NRCSM, Beijing, China). Additionally, copper nitrate $\left(\mathrm{Cu}\left(\mathrm{NO}_{3}\right)_{2}, 99.9 \%\right)$, hydrochloric acid $(\mathrm{HCl}, 99.9 \%)$, sulfuric acid $\left(\mathrm{H}_{2} \mathrm{SO}_{4}, 99.8 \%\right)$ nitric acid $\left(\mathrm{HNO}_{3}, 99.8 \%\right)$, hydrofluoric acid ( $\left.\mathrm{HF}, 40 \%\right)$, hydrogen peroxide $\left(\mathrm{H}_{2} \mathrm{O}_{2}, 30 \%\right)$, toluene $\left(\mathrm{C}_{7} \mathrm{H}_{8}, 99.5 \%\right)$, potassium chloride $(\mathrm{KCl}, 99.9 \%)$, and ethanol absolute $\left(\mathrm{C}_{2} \mathrm{H}_{6} \mathrm{O}\right)$ were obtained from Sailboat Chemical Reagent Technology Co., Ltd. 
(Tianjin, China). The reagents and solvents used are of analytical grade and need no further purification unless otherwise specified.

\subsection{Preparation of Nanoporous Silicon (NPSi)}

The silicon raw material was pre-washed with ammonia, hydrogen peroxide and deionized water (volume ratio 2:2:5) to remove surface organic impurities, and then washed with hydrochloric acid, hydrogen peroxide and deionized water (volume ratio 2:2:5) to remove oxides. Finally, a 5\% HF solution was used for washing to obtain purified silicon powder [25].

The copper nanoparticles were chemically deposited on the silicon surface for $1 \mathrm{~min}$ and then placed in a mixed solution of $\mathrm{HF}(40 \%)$ and $\mathrm{H}_{2} \mathrm{O}_{2}(5 \mathrm{mM})$ for chemical etching [22]. After $1 \mathrm{~h}$ reaction, the etched silicon powder was filtered and cleaned with $30 \%$ nitric acid to remove residual nano- $\mathrm{Cu}$ particles. After filtration, the porous silicon powder was washed with ethanol and deionized water repeatedly until the $\mathrm{pH}$ was neutral. Finally, the filtered porous silicon powder was dried under vacuum at $60^{\circ} \mathrm{C}$ for $12 \mathrm{~h}$.

To increase the active group on the surface of porous silicon powder, the dried silicon powder was stirred for $3 \mathrm{~h}$ in a solution with the $\mathrm{H}_{2} \mathrm{SO}_{4} / \mathrm{H}_{2} \mathrm{O}_{2}$ volume ratio of 3:1 [26]. After activation, it was filtered and washed repeatedly with ethanol and deionized water until the $\mathrm{pH}$ was neutral. Finally, the filtered porous silicon powder was dried under vacuum at $60{ }^{\circ} \mathrm{C}$ for $12 \mathrm{~h}$.

\subsection{Synthesis of TEPA-GTS-NPSi}

The preparation roadmap of TEPA-GTS-NPSi is shown in Scheme 1.
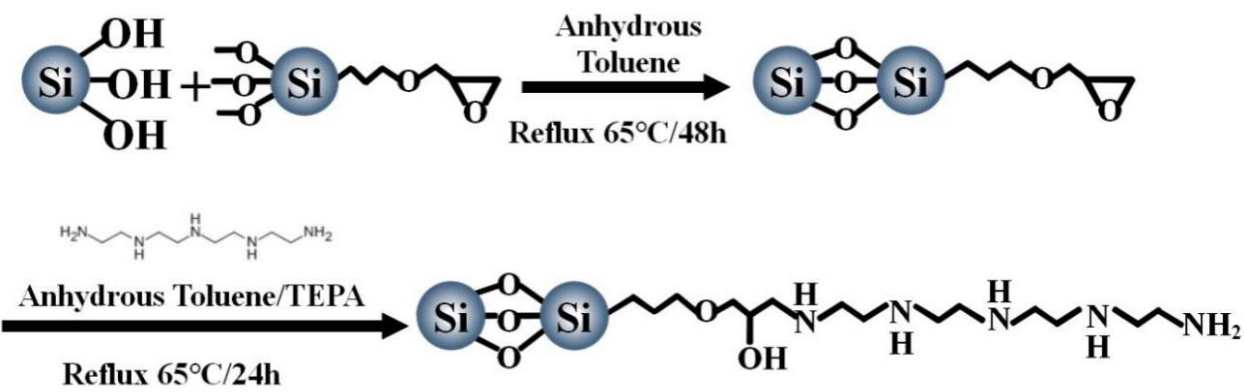

Scheme 1. The synthesis process of TEPA-GTS-NPSi.

First, (3-glycidyloxypropyl) trimethoxy-silane (3-GTS) (5 mL), NPSi (2 g) and anhydrous toluene $(30 \mathrm{~mL})$ were mixed and stirred for reflux at $60{ }^{\circ} \mathrm{C}$ for $24 \mathrm{~h}$. After being filtered, this was washed with ethanol 5 times and dried under vacuum at $60{ }^{\circ} \mathrm{C}$ for $12 \mathrm{~h}$ [27]. The products obtained in the first step are denoted as GTS-NPSi. Secondly, GTS-NPSi (1.5 g), TEPA (tetraethylenepentamine) and anhydrous toluene $(30 \mathrm{~mL})$ were mixed and stirred for reflux at $60{ }^{\circ} \mathrm{C}$ for $24 \mathrm{~h}$ [28]. The products obtained in the second step are denoted as TEPA-GTS-NPSi.

\subsection{Characterization of Materials}

FT-IR (Nicoletis10) measurements were used to investigate the functional groups on the surface of the adsorbent. The FTIR spectrophotometer (Nicoletis10, Thermo Fisher Scientific, Waltham, MA, USA) had a wave number range from 4000 to $400 \mathrm{~cm}^{-1}$. The element composition and the existing form of the element were determined by X-ray photoelectron spectroscopy (XPS, K-Alpha+, Thermo Fisher Scientific, Waltham, MA, USA) with a $\mu$-spot monochromatic $\mathrm{AlK} \alpha$ source $(\mathrm{AlK} \alpha$, pass energy $=50.0 \mathrm{eV}$ (wide scan) and $30 \mathrm{eV}$ (narrow scan), Voltage $=10 \mathrm{kV}$, Current $=20 \mathrm{~mA}$ ). The specific surface area and pore size of the TEPA-GTS-NPSi were determined utilizing a $\mathrm{N}_{2}$ adsorption/desorption specific surface area meter (Quadrasorb-evo, Quantachrome Corporation, Boynton Beach, FL, USA). TGA (NETZSCH, Selbu, Germany) were used to investigate the number of organic functional groups. The morphology of silicon powder was characterized by FE-SEM (Nova 
NanoSEM 450, 10 kV, FEI, Hillsboro, OR, USA). ICP-OES (Leeman prodigy 7, Teledyne Leeman Labs, Inc., Hudson, NH, USA) was used to measure the concentration of metal ions in the adsorbed solution.

\subsection{Batch Adsorption Studies}

The effect of $\mathrm{pH}$ on the adsorption capacity was investigated with $20 \mathrm{~mL}$ of $100 \mathrm{mg} / \mathrm{L}$ $\mathrm{As}(\mathrm{V})$ solutions in the $\mathrm{pH}$ range of $1-8$ at $25^{\circ} \mathrm{C}$. The effect of time on the adsorption capacity was analyzed at $\mathrm{pH}=7, \mathrm{As}(\mathrm{V})$ concentration of $100 \mathrm{mg} / \mathrm{L}$ and $25^{\circ} \mathrm{C}$ for different adsorption times $(0.5-120 \mathrm{~min})$. The effect of initial $\mathrm{As}(\mathrm{V})$ concentration on the adsorption capacity was researched at $\mathrm{pH}=7$ and $25^{\circ} \mathrm{C}$ for $2 \mathrm{~h}$ with different initial concentrations (10-150 mg/L). The effect of dosage on the adsorption capacity was investigated with $20 \mathrm{~mL}$ of $20 \mathrm{mg} / \mathrm{L} \mathrm{As}(\mathrm{V})$ solutions at $25^{\circ} \mathrm{C}$ for $2 \mathrm{~h}$. The dosage range of adsorbent was $10-35 \mathrm{mg}$. The removal efficiency $(\mathrm{R})$ and the adsorption capacity $\left(q_{e}\right)$ were calculated by the following Equations (1) and (2), respectively:

$$
\begin{gathered}
q_{e}=\frac{\left(C_{0}-C_{e}\right) V}{m} \\
\mathrm{R}=\left(1-\frac{C_{e}}{C_{0}}\right) \times 100 \%
\end{gathered}
$$

where $C_{0}$ and $C_{e}$ are initial and equilibrium concentration of $\mathrm{As}(\mathrm{V})$ in aqueous solution $(\mathrm{mg} / \mathrm{L})$, respectively. $V$ is the volume of solution, and $\mathrm{m}$ is the mass of absorbent.

To study the recycling properties of adsorbents, $1 \mathrm{~mol} / \mathrm{L}$ of $\mathrm{HCl}$ solution was used as the desorption agent. After the adsorption, the adsorbent was desorbed in desorption agent for $3 \mathrm{~h}$ to study the cyclic usability of the adsorbent. Then, the adsorbent was washed with distilled water several times and vacuum dried at $25^{\circ} \mathrm{C}$ for $24 \mathrm{~h}$ for the next round of adsorption. The above procedures were repeated five times.

\section{Results and Discussion}

\subsection{Characterization of the Amino-Functionalized Nanoporous Silicon}

The morphology and microstructure of the prepared porous silicon and organic functionalized porous silicon were characterized by SEM, as shown in Figure 1. As seen in Figure 1a, the raw material of DWSSP is mainly in the form of debris, with relatively flat particle surface and no obvious hole structure. Compared with the morphology of the unetched sample (Figure 1b), the morphology of amino-functionalized nanoporous silicon is clearly changed, pore structures start to appear on the particle surface, and the pore structure mainly appears on the particle surface after etching. This may be attributed to the fact that $\mathrm{Cu}$ nanoparticles accelerate the rate of local electrochemical reactions on the surface of silicon particles in the etching solution system. Meanwhile, the size of silicon particles decreased, indicating that the nanoporous silicon with pore structure has been prepared by diamond wire-cut waste.

Fourier transform infrared spectroscopy (FT-IR) and X-ray photoelectron spectroscopy (XPS) were used to characterize functional groups on the surface of organic functionalized porous silicon, and the infrared spectrum of GTS-NPSi and TEPA-GTS-NPSi was obtained as shown in Figure 2.

The ligands of the two adsorbents are trimethoxy-silane and tetraethylenepentamine, respectively. Therefore, it was found that the peak at $470 \mathrm{~cm}^{-1}$ is corresponding to the bending vibration of $\mathrm{Si}-\mathrm{O}-\mathrm{Si}$, the peak at $803 \mathrm{~cm}^{-1}$ is ascribed to the symmetric stretching of $\mathrm{Si}-\mathrm{O}-\mathrm{Si}$, and $1101 \mathrm{~cm}^{-1}$ is corresponding to the stretching vibration of $\mathrm{Si}-\mathrm{O}-\mathrm{Si}$ [29]. The peaks at 3440 and $1630 \mathrm{~cm}^{-1}$ were corresponding to $\mathrm{O}-\mathrm{H}$ stretching vibration and deformation vibration, respectively. Moreover, in the spectrum of GTS-NPSi and TEPA-GTS-NPSi, the peaks at 2934 and $2834 \mathrm{~cm}^{-1}$ were corresponding to the $\mathrm{C}-\mathrm{H}$ stretching vibration, indicating that organic silane was successfully grafted onto porous silicon nanoparticles' surface [30]. In the spectrum of TEPA-GTS-NPSi, the band at $1384 \mathrm{~cm}^{-1}$ is due to the 
$-\mathrm{NH}_{2}$ and $-\mathrm{NH}$ bending vibrations [31]. These indicate that organic functional groups have successfully grafted on the surface of porous silicon.

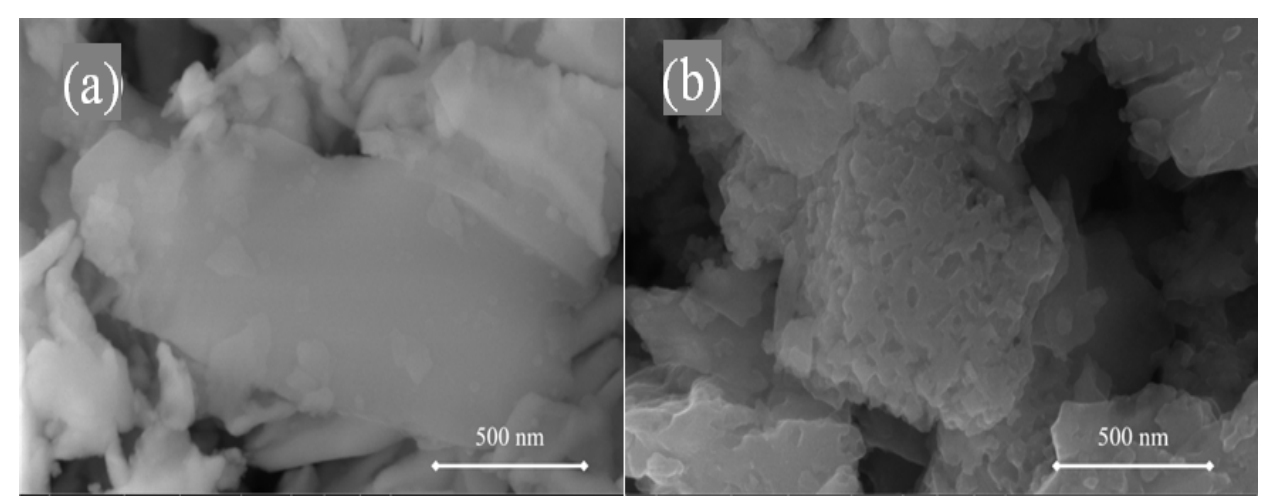

Figure 1. SEM images of diamond wire saw silicon powder (DWSSP), (a) and porous silicon (b).

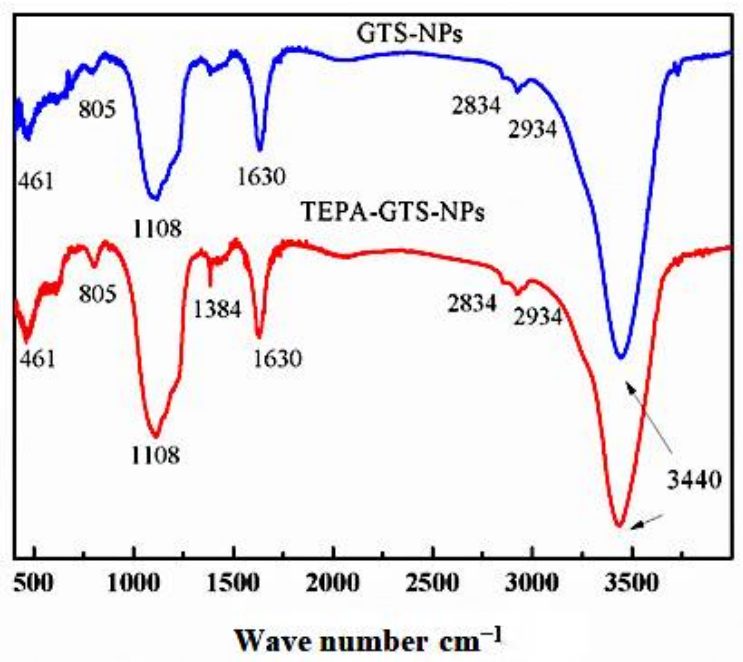

Figure 2. FT-IR spectra of GTS-NPSi and TEPA-NPSi.

To determine the grafting amount of organic functional groups, thermogravimetric analysis (TGA) was used to verify it. Thermogravimetric diagrams of NPSi, GTS-NPSi and TEPA-GTS-NPSi are shown in Figure 3. Among them, the mass loss of NPSi, GTS-NPSi and TEPA-GTS-NPSi was $6.6 \%, 13.6 \%$, and $20.7 \%$, respectively. Considering the decomposition of the organic group and evaporation of water, the amounts of grafted GTS and TEPA groups were $7.0 \%$ and $7.1 \%$, respectively.

\subsection{Adsorption Performance}

\subsubsection{Effect of $\mathrm{pH}$ on $\mathrm{As}(\mathrm{V})$ Adsorption}

The effect of initial $\mathrm{pH}$ values on the $\mathrm{As}(\mathrm{V})$ adsorption capacity of TEPA-GTS-NPSi is shown in Figure 4. In the experimental $\mathrm{pH}$ range of 1.0-8.0, with the increase of $\mathrm{pH}$ value, the adsorption capacity of TEPA-GTS-NPSi shows a trend of first increasing and then stabilizing with the increase of $\mathrm{pH}$. After $\mathrm{pH}=4$, the increasing trend weakened and reached stability near $\mathrm{pH}=7$. However, the adsorption capacity of the NPSi remains at a low level in all $\mathrm{pH}$ ranges.

The different $\mathrm{As}(\mathrm{V})$ species at different $\mathrm{pH}$ values are also shown in Figure 4 . At the low $\mathrm{pH}$ value, part of $\mathrm{As}(\mathrm{V})$ was electrically neutral $\left(\mathrm{H}_{3} \mathrm{AsO}_{4}\right)$. As the $\mathrm{pH}$ increased, the main form of $\mathrm{As}(\mathrm{V})$ was $\mathrm{H}_{2} \mathrm{AsO}_{4}{ }^{-}$and $\mathrm{HAsO}_{4}{ }^{2-}$, At this point, $\mathrm{As}(\mathrm{V})$ species are electronegative; however, the main form of amino in TEPA-GTS-NPSi is $-\mathrm{NH}_{3}{ }^{+}\left(\mathrm{pKa}_{(\mathrm{NH}} \cdot \mathrm{H}_{2} \mathrm{O}\right)$ = 9.3) $[29,32]$, which is electropositive. In the adsorption process, $\mathrm{H}_{2} \mathrm{AsO}_{4}{ }^{-}$and $\mathrm{HAsO}_{4}{ }^{2-}$ 
capture the $\mathrm{H}^{+}$ion in the $-\mathrm{NH}_{3}{ }^{+}$; thus, the $\mathrm{As}(\mathrm{V})$ species are adsorbed by TEPA-GTS-NPSi through electrochemical action.

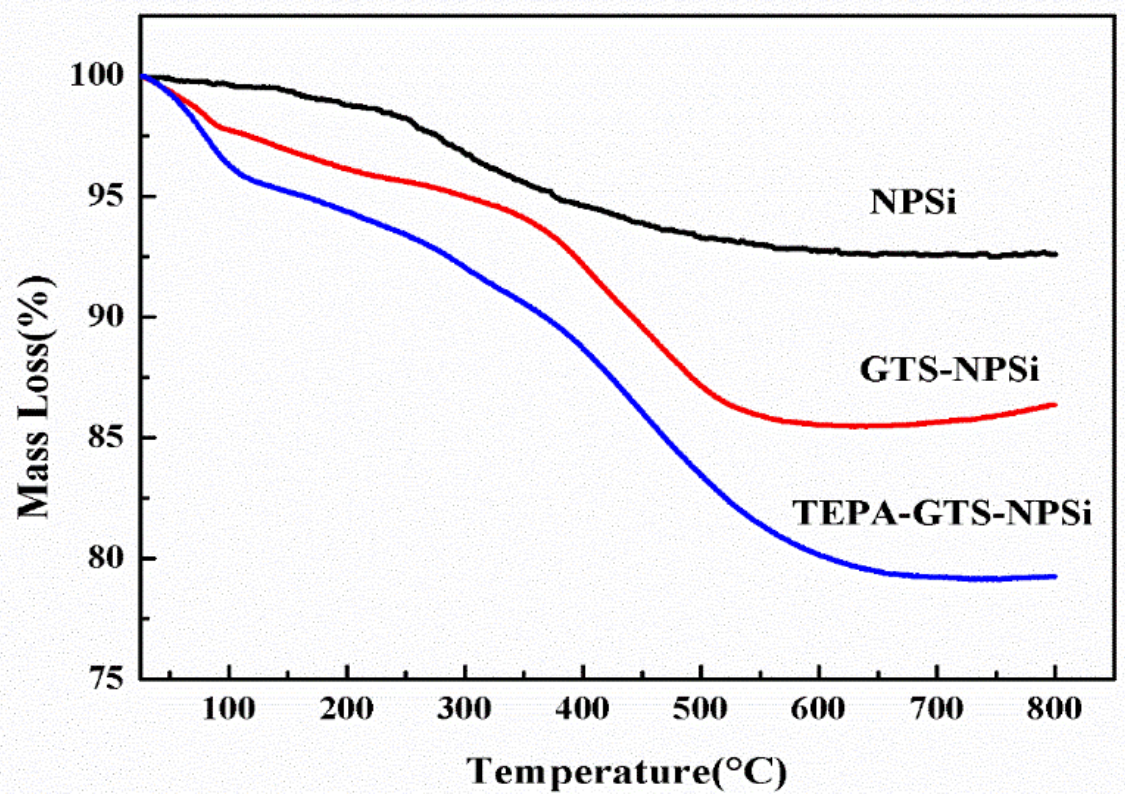

Figure 3. TGA analysis of NPSi GTS-NPSi and TEPA-GTS-NPSi.

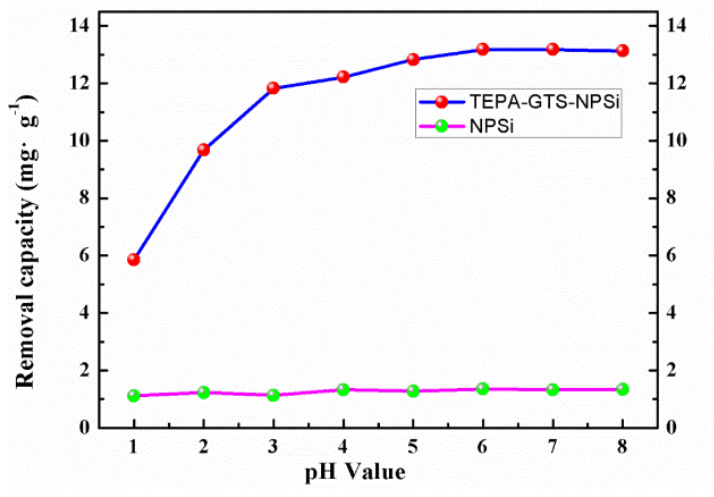

(a)

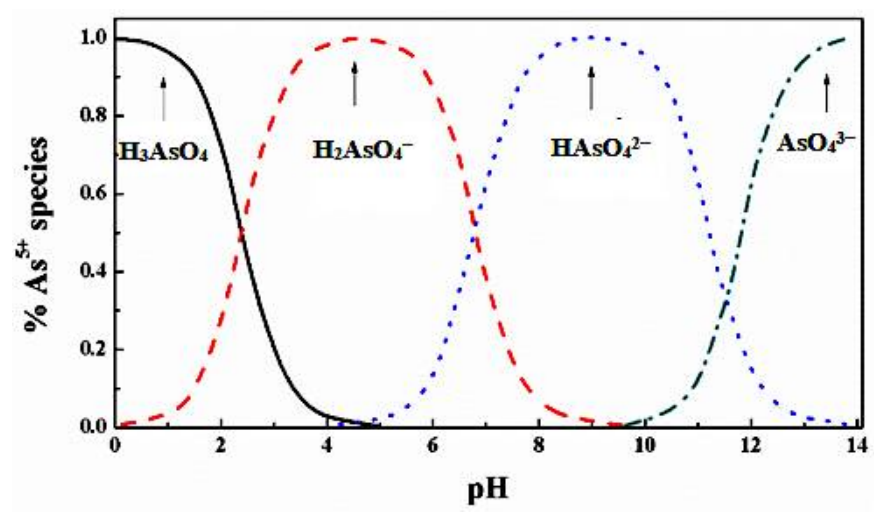

(b)

Figure 4. Effect of initial $\mathrm{pH}$ on $\mathrm{As}(\mathrm{V})$ adsorption $(\mathbf{a})$ and species of $\mathrm{As}(\mathrm{V})$ with a range of solution $\mathrm{pH}(\mathbf{b})$.

\subsubsection{Effect of the Contact Time and Adsorption Kinetics}

Adsorption rate is an important parameter used to characterize the properties of adsorbent; fast adsorption is more beneficial to practical application. The effect of the adsorption time on the $\mathrm{As}(\mathrm{V})$ adsorption by TEPA-GTS-NPSi is presented in Figure 5. Obviously, $\mathrm{As}(\mathrm{V})$ adsorption by the adsorbent can be viewed in two stages as follows: a rapid adsorption stage and slow adsorption stage. The whole adsorption process consists of the first $10 \mathrm{~min}$ rapid phase, and the reaction reaches equilibrium at around $60 \mathrm{~min}$. In the initial rapid phase, the adsorption rate is very fast, and the adsorption capacity is greatly increased, which is because adsorbent surfaces are rich in active sites, the mass transfer impetus caused by the concentration difference and the high chemical potential. After $30 \mathrm{~min}$, the adsorption tended to be stable and the adsorption of adsorbent reached saturation. 


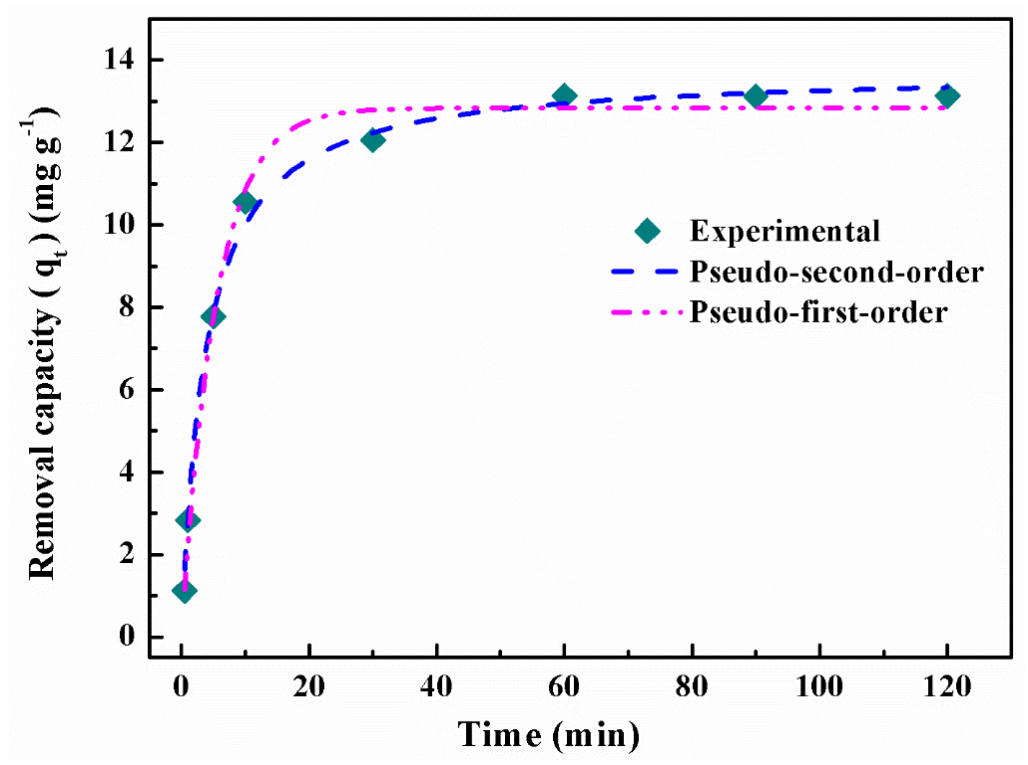

Figure 5. Effect of contact time on $\mathrm{As}(\mathrm{V})$ adsorption.

To evaluate the kinetic mechanism, two different kinetic models were employed to describe the adsorption process. The pseudo-first-order and pseudo-second-order models are represented as Equations (3) and (4):

$$
\begin{gathered}
\ln \left(q_{e}-q_{t}\right)=\ln _{q_{e}}-k_{1} t \\
\frac{t}{q_{t}}=\frac{1}{k_{2} q_{e}^{2}}+\frac{t}{q_{e}}
\end{gathered}
$$

where the $k_{1}\left(\mathrm{~min}^{-1}\right)$ is the rate constant of pseudo-first-order, $k_{2}[\mathrm{~g} /(\mathrm{mg} \cdot \mathrm{min})]$ is the rate constant of pseudo-second-order, $q_{e}(\mathrm{mg} / \mathrm{g})$ and $q_{t}(\mathrm{mg} / \mathrm{g})$ are the adsorption capacity at equilibrium time and adsorption capacity at time $(t)$, respectively.

The results of nonlinear fitting are also shown in Figure 5, and the kinetic constants and correlation coefficients $\left(\mathrm{R}^{2}\right)$ were listed in Table 1.

Table 1. Comparison of the pseudo-first and pseudo-second-order constants.

\begin{tabular}{cc}
\hline Pseudo-First-Order Model & Pseudo-Second-Order Model \\
\hline$k_{1}=0.18633 \mathrm{~min}^{-1}$ & $k_{2}=0.01953 \mathrm{~g} \cdot \mathrm{mg}^{-1} \cdot \mathrm{min}^{-1}$ \\
$\mathrm{R}^{2}=0.9909$ & $\mathrm{R}^{2}=0.9952$ \\
\hline
\end{tabular}

According to the fitting results, the correlation coefficient of the pseudo-second-order model is significantly higher than that of the pseudo-first-order model $\left(R^{2}=0.9909\right)$. The pseudo-second-order model assumed that the determining step of the adsorption rate is a chemical reaction. This indicates that the adsorption of As $(\mathrm{V})$ on TEPA-GTS-NPSi is mainly due to the chemical adsorption.

\subsubsection{Adsorption Mechanism}

To gain further insight into the As(V) adsorption mechanism of TEPA-GTS-NPSi, XPS analysis of TEPA-GTS-NPSi before and after $\mathrm{As}(\mathrm{V})$ adsorption was performed, as shown in Figure 6. According to the comparison of XPS spectra before and after adsorption, in the As3d spectra (Figure 6d) after adsorption, a spectrum peak of binding energy of $45.2 \mathrm{eV}$ was found, which was corresponding to the peak of $A s 3 \mathrm{~d}_{5 / 2}$ [33]. The appearance of this spectrum peak initially indicates that $\mathrm{As}(\mathrm{V})$ was successfully adsorbed on the TEPA-GTSNPSi functionalized porous silicon adsorbents. As can be seen from the TEPA-GTS-NPSi $\mathrm{N} 1 \mathrm{~s}$ map (Figure 6c), after adsorption, the original $-\mathrm{NH}_{2}$ corresponding to $398.5 \mathrm{eV}$ and 
$-\mathrm{NH}_{3}{ }^{+}$corresponding to $400.5 \mathrm{eV}$ were also detected [34]. In addition,-the strong peaks of $\mathrm{NH}_{3}{ }^{+}$and the significantly lower intensity peaks of $-\mathrm{NH}_{2}$ after adsorption can clearly be seen (Figure $6 \mathrm{c}$ ); this also shows that in the process of adsorption, TEPA-GTS-NPSi adsorbent of amino was the main form of $-\mathrm{NH}_{3}{ }^{+}$. Based on the above results, it is suggested that the main reason for the adsorption of $\mathrm{As}^{5+}$ by TEPA-GTS-NPSI functionalized porous silicon under weak acidic conditions is the interaction between $-\mathrm{NH}_{3}{ }^{+}$and $\mathrm{H}_{2} \mathrm{AsO}_{4}{ }^{-}$to achieve the adsorption effect.
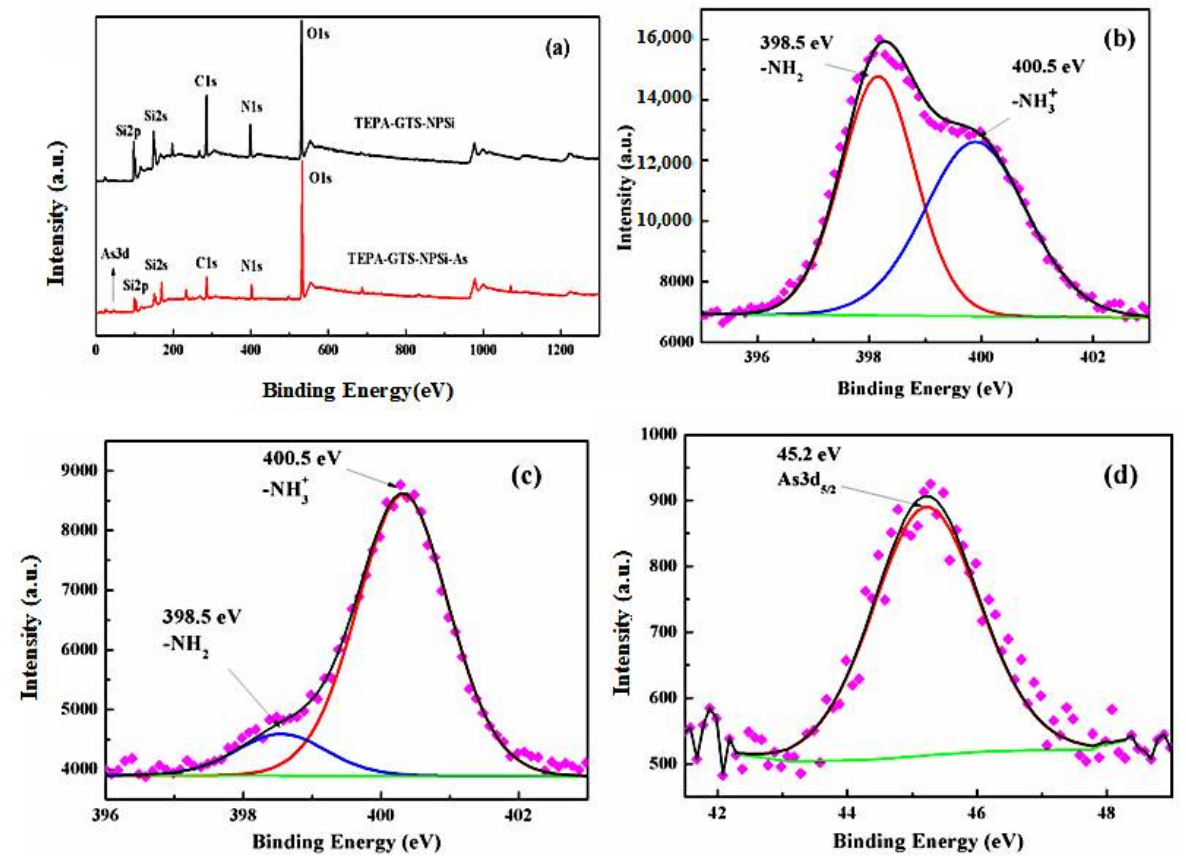

Figure 6. XPS analysis of before and after adsorption: (a) Wide-scan spectra of TEPA-GTS-NPSi before and after adsorption; (b) N1s spectra of TEPA-GTS-NPSi; (c) N1s spectra of TEPA-GTS-NPSi after adsorption; (d) As3d spectra of TEPA-GTS-NPSi after adsorption.

\subsubsection{Effect of Initial $\mathrm{As}(\mathrm{V})$ Concentration and Adsorption Isotherms}

The effect of initial concentration on As(V) removal by TEPA-GTS-NPSi was investigated in Figure 7.

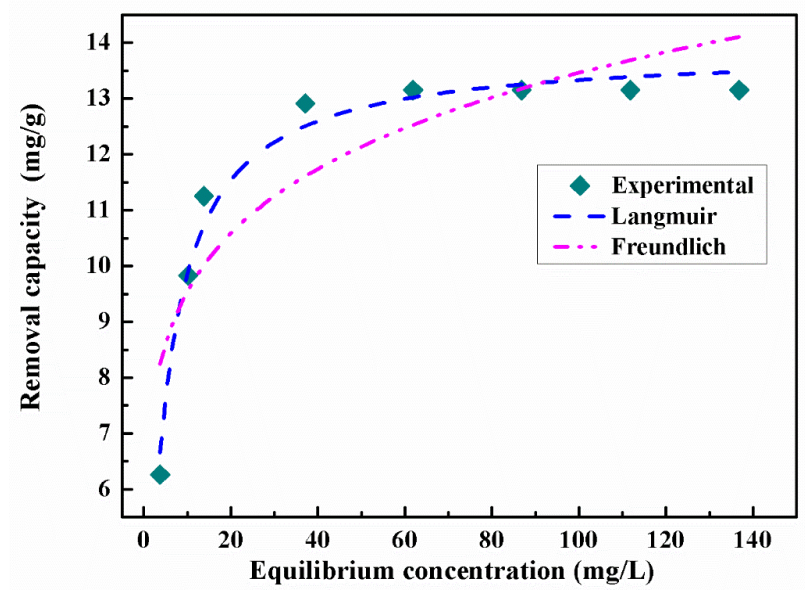

Figure 7. Effect of initial concentration on $\mathrm{As}(\mathrm{V})$ adsorption.

The equilibrium adsorption capacity increased with the increase of the concentration of $\mathrm{As}(\mathrm{V})$ at first. When the concentration was lower than $100 \mathrm{mg} / \mathrm{L}$, the adsorption capacity increased with the increase of the concentration, but the trend of increase gradually slowed. 
When the concentration was higher than $100 \mathrm{mg} / \mathrm{L}$, the saturated adsorption capacity finally reached $(13.2 \mathrm{mg} / \mathrm{g})$. This is because when the concentration of $\mathrm{As}(\mathrm{V})$ is low, the functional groups are not fully occupied by $\operatorname{As}(\mathrm{V})$, and there are still excess ligand functional groups that can continue to react with $\mathrm{As}(\mathrm{V})$. Therefore, the adsorption capacity is relatively low. As the initial concentration of $\mathrm{As}(\mathrm{V})$ continued to increase, the active site of TEPA-GTS-NPSi continued to adsorb with As(V) through electrostatic interaction, so the adsorption capacity increased. By comparing with some previous reports in Table 2, the TEPA-GTS-NPSi hybrid materials derived from cutting waste show an acceptable adsorption capacity.

Table 2. As(V) adsorption capacities for different adsorbents.

\begin{tabular}{ccc}
\hline Adsorbent & Adsorption Capacity $\mathbf{( m g} / \mathbf{g})$ & Reference \\
\hline Magnetite & 17.2 & {$[35]$} \\
$\mathrm{ZrO}_{2}$-sawdust & 12 & {$[36]$} \\
Organic biochar & 16.2 & {$[37]$} \\
Mt-Arg & 16.5 & {$[38]$} \\
NPSi & 13.2 & This work \\
\hline
\end{tabular}

Moreover, to evaluate the isotherms mechanism, Langmuir and Freundlich isotherm models were employed to describe the interaction between As(V) and TEPA-GTS-NPSi. The Langmuir isotherms model can be described by the Equation (5).

$$
q_{e}=\frac{q_{\max } \times K_{L} \times C_{e}}{1+K_{L} \times C_{e}}
$$

where $q_{e}(\mathrm{mg} / \mathrm{g})$ is the equilibrium absorption capacity, $C_{e}(\mathrm{mg} / \mathrm{L})$ is the concentration at equilibrium, $q_{m}(\mathrm{mg} / \mathrm{g})$ is the maximum adsorption capacity and $K_{\mathrm{L}}(\mathrm{L} / \mathrm{g})$ is the equilibrium constant of the Langmuir isotherms model.

The Freundlich isotherms model can be described by the Equation (6):

$$
q_{e}=K_{F} \times C_{e}^{\frac{1}{n}}
$$

where $C_{e}(\mathrm{mg} / \mathrm{L})$ is the concentration at equilibrium, $K_{F}$ and $\mathrm{n}$ are the constants of Freundlich isotherms models.

The results of nonlinear fitting are also shown in Figure 8, and the fitting parameters and correlation coefficients were listed in Table 3. Compared with the fitting coefficient $\left(R^{2}\right)$ of the Langmuir and Freundlich adsorption isotherms models, the Langmuir model was more in line with the adsorption process of TEPA-GTS-NPSi adsorbent on As(V) than the Freundlich model. Moreover, the maximum adsorption capacity obtained by the Langmuir isotherms model was $13.87 \mathrm{mg} / \mathrm{g}$, which was close to the experimental adsorption capacity of $13.2 \mathrm{mg} / \mathrm{g}$. It also indicated that the adsorption of As(V) by TEPA-GTS-NPSi was mostly monolayer adsorption.

Table 3. Constants of Langmuir and Freundlich isotherms.

\begin{tabular}{cc}
\hline Langmuir Adsorption Isotherm & Freundlich Adsorption Isotherm \\
\hline$q_{\max }=13.8754 \mathrm{mg} \cdot \mathrm{g}^{-1}$ & $K_{F}=6.7737$ \\
$K_{L}=0.2483 \mathrm{~L} \cdot \mathrm{mg}^{-1}$ & $n=6.7050$ \\
$\mathrm{R}^{2}=0.9782$ & $\mathrm{R}^{2}=0.7613$ \\
\hline
\end{tabular}

\subsubsection{Effect of Dosage and Adsorption Limit}

To study the lower limit of adsorption of TEPA-GTS-NPSi adsorbent for As $(\mathrm{V})$, with the same amount of $\mathrm{As}(\mathrm{V})$, different amounts of adsorbent were used for the experiment. The result is shown in Figure 8. At the low amount of adsorbent, with the increase of the 
amount of TEPA-GTS-NPSi adsorbent, the adsorption capacity slightly increased, but when the amount of adsorbent exceeded $25 \mathrm{mg}$, the adsorption capacity decreased. However, in the process in which the amount of adsorbent increased, the removal rate increased steadily and remained stable after the amount of adsorbent exceeded $25 \mathrm{mg}$. This is because at the low dosage, $\mathrm{As}(\mathrm{V})$ concentration is relatively high, and the concentration results in a high mass transfer impetus and high chemical potential; as a result, the adsorption quantity increases slightly. When dosage exceeds $25 \mathrm{mg}$, the residual concentration of $\mathrm{As}(\mathrm{V})$ in the solution was not enough, and the mass transfer impetus and chemical potential was low; thus, the adsorbent cannot absorb the remaining As $(\mathrm{V})$. At this point, the concentration of As(V) in the solution was the lowest adsorption limit of TEPA-GTS-NPSi adsorbent, and the lower adsorption limit was $3 \mathrm{mg} / \mathrm{L}$.

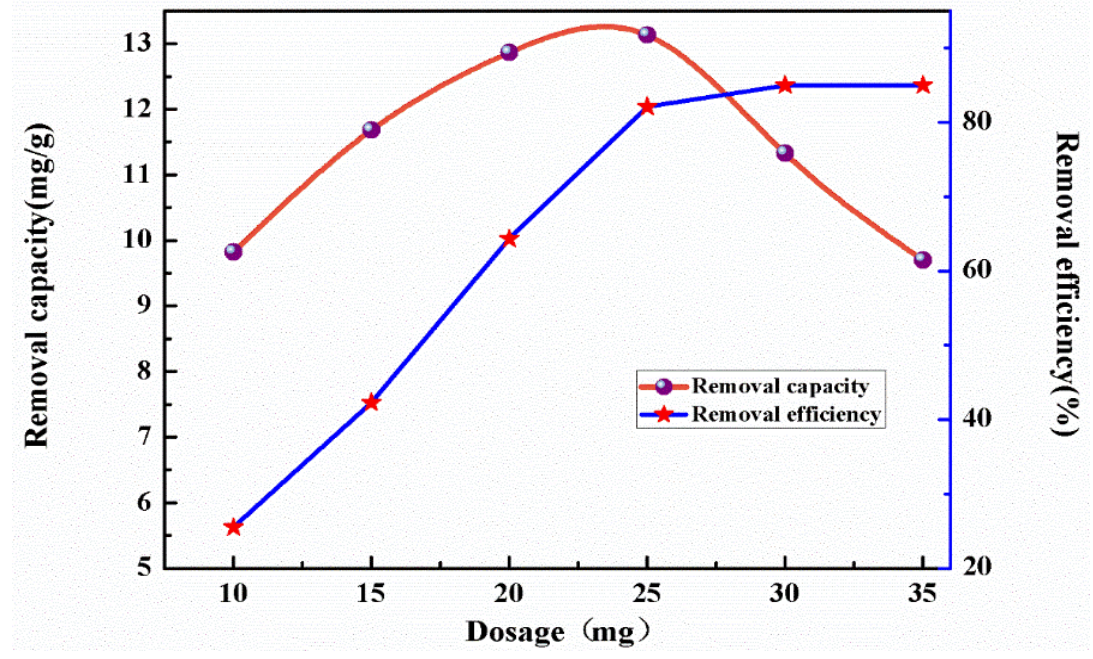

Figure 8. Effect of dosage on As(V) adsorption.

\subsubsection{Regeneration and Reuse of TEPA-GTS-NPSi}

The reusability of adsorbent is the key factor to judge the value of adsorbent. Therefore, in this study, the adsorption-desorption in the removal of $\mathrm{As}(\mathrm{V})$ was investigated. The adsorbents were initially loaded with $\mathrm{As}(\mathrm{V})$, then eluted with $\mathrm{HNO}_{3}$ solution $\left(0.1 \mathrm{~mol} \cdot \mathrm{L}^{-1}\right)$, and then repeatedly utilized for $\mathrm{As}(\mathrm{V})$ capture. The results of the recyclability studies are shown in Figure 9.

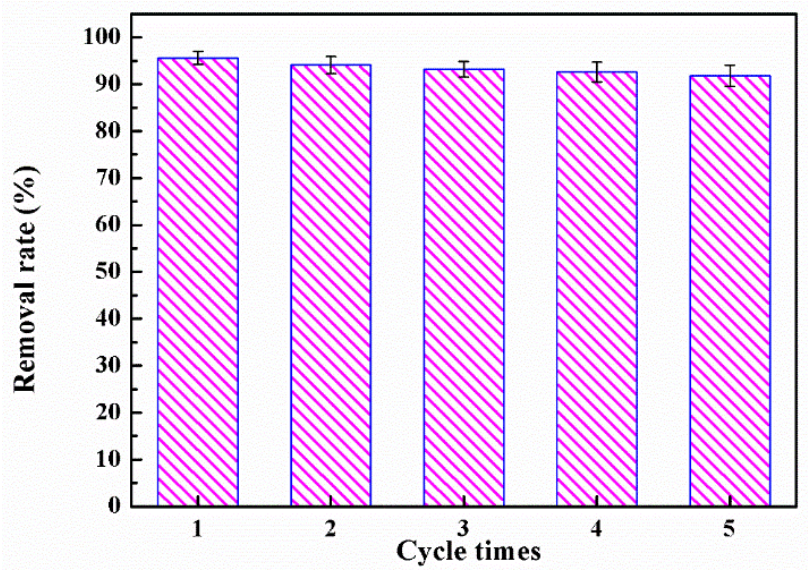

Figure 9. Reusability adsorption on TEPA-GTS-NPSi on As(V) adsorption.

The adsorption efficiency of TEPA-GTS-NPSi adsorbent was still good after five cycles. The adsorption efficiency was $95.6 \%$ after the first cycle and $91.8 \%$ after the fifth cycle. This 
is mainly because some functional groups on the surface were lost or became inactivated in the circulation. The results indicate that TEPA-GTS-NPSi has good regeneration capability for $\mathrm{As}(\mathrm{V})$ adsorption.

\subsubsection{Practical Application of Industrial Wastewater}

The application of adsorbent in actual wastewater is the most intuitive way to test the effect of an adsorbent. Thus, the TEPA-GTS-NPSi adsorbent was used for adsorption in actual wastewater which was obtained from a factory in Yunnan, China. The results were shown in Table 4.

Table 4. The comparison of industrial wastewater before and after TEPA-GTS-NPSi treatment.

\begin{tabular}{cccc}
\hline & As & Cu & Zn \\
\hline Before (mg/L) & 297.6 & 28.28 & 17.66 \\
After (mg/L) & 272.86 & 26.36 & 16.84 \\
$\begin{array}{c}\text { Adsorption capacity } \\
\text { (mg/g) }\end{array}$ & 12.37 & 0.96 & 0.41 \\
\hline
\end{tabular}

Most industrial wastewater contains $\mathrm{As}, \mathrm{Cu}$, and $\mathrm{Zn}$. As can be seen from Figure 4, the adsorption capacity of TEPA-GTS-NPSI adsorbent for As was $12.37 \mathrm{mg} / \mathrm{g}$, which reached $93.71 \%$ of the theoretical maximum adsorption capacity at about $\mathrm{pH} 7(13.87 \mathrm{mg} / \mathrm{g})$. The results show that the adsorption effect of TEPA-GTS-NPSI adsorbent on As is better than that on copper and zinc, and it has certain practicability in the treatment of industrial wastewater containing arsenic.

\subsubsection{DFT Analysis}

The geometric optimizations were conducted by density function theory (DFT) at B3LYP level with 6-311++G(d, p) basis. All optimization of electronic and geometrical structures was performed by Gaussian 09 suite of program. According to the result of $\mathrm{pH}$ and XPS, the optimized geometries of TEPA-GTS, $\mathrm{H}_{3} \mathrm{AsO}_{4}$ and As-TEPA-GTS are shown in Figure 10.

It is can be seen that the $\mathrm{H}_{3} \mathrm{AsO}_{4}$ group mainly adsorbed by $-\mathrm{NH}_{2}$ group on the functional molecule after the adsorption process. Table 5 presents the selected structural parameter of optimized geometries on bond length.

According to the bond length, it is obvious that after the adsorption process, the bond lengths of $\mathrm{N}-\mathrm{H}$ and $\mathrm{O}-\mathrm{H}$ are getting longer; however, the bond length of $\mathrm{O}-\mathrm{H}$ is shorter than that of before adsorption. This phenomenon can be explained by the charge action between TEPA-GTS functional molecule and $\mathrm{H}_{3} \mathrm{AsO}_{4}$, resulting in the bond length changes. Also, the bond length of N1-H6 is $1.64556 \AA$; this atomic distance indicates a strong hydrogen bond between them [39].

In addition, the NBO charge distributions are shown in Table 5 and the contour maps of As-TEPA-GTS are shown in Figure 11.

According to Table 6, the NBO charge of selected atoms has increased after the adsorption process; this indicates that there is a transfer of charge in these atoms which causes the adsorption. The electron density spread over $\mathrm{N}$ and $\mathrm{O}-\mathrm{H}$ from Figure 10, which confirms the strong interaction of TEPA-GTS and $\mathrm{H}_{3} \mathrm{AsO}_{4}$ [40]. Also, second-order perturbation theory analysis was applied to explore the interaction between donor atom and metal ion, and the corresponding E(2) stabilization energy was employed to measure the interaction between the donor and acceptor. During the adsorption process, the lone pair electrons of $\mathrm{N}$ are the donor, the antibonding orbital of $\mathrm{H6}-\mathrm{O} 5$ is the acceptor, and the stability energy of $\mathrm{E}(2)$ of $\mathrm{LP}(\mathrm{N} 1) \rightarrow \mathrm{BD} \times(\mathrm{H} 6-\mathrm{O} 5)$ is $40.75 \mathrm{kcal} / \mathrm{mol}$. The results indicate that the interaction between the $\mathrm{N}$ atom and the $\mathrm{H}-\mathrm{O}$ bond dominated the adsorption. All the results show that the adsorption mechanism is mainly due to the strong interaction between the terminal amino group and arsenic species. 

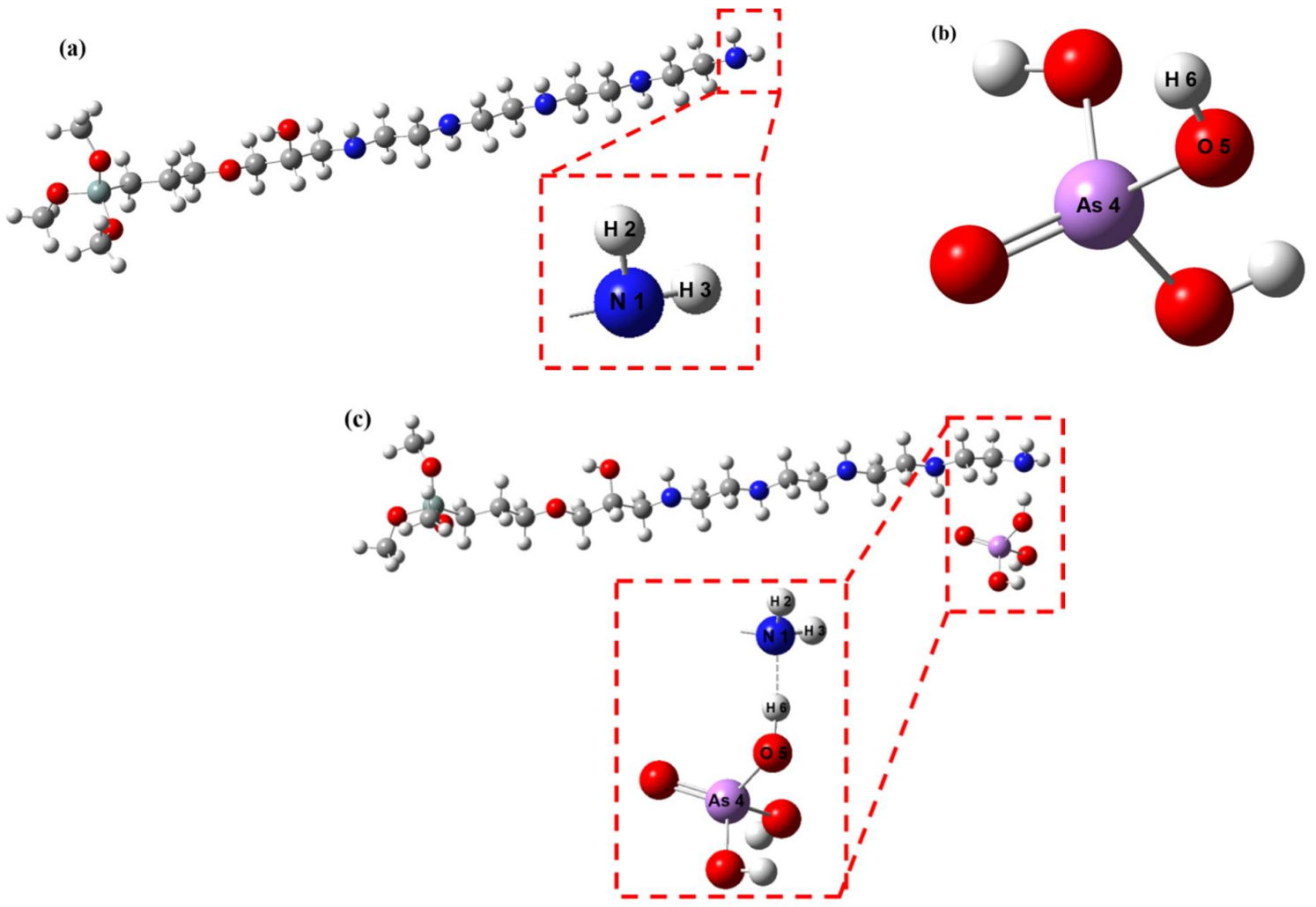

Figure 10. Optimized structure of (a) TEPA-GTS; (b) H3AsO4; (c) As-TEPA-GTS.

Table 5. Selected structural parameter of optimized geometries on bond length.

\begin{tabular}{|c|c|c|c|}
\hline \multicolumn{2}{|c|}{ TEPA-GTS } & \multicolumn{2}{|c|}{ As-TEPA-GTS } \\
\hline N 1-H 2 & 1.01573 & N 1-H 2 & 1.01645 \\
\hline N 1-H 3 & 1.01429 & N 1-H 3 & 1.01570 \\
\hline \multicolumn{2}{|c|}{$\mathrm{H}_{3} \mathrm{ASO}_{4}$} & N 1-H 6 & 1.64556 \\
\hline As $4-\mathrm{O} 5$ & 1.74407 & As $4-\mathrm{O} 5$ & 1.70956 \\
\hline O 5-H 6 & 0.96413 & O 5-H 6 & 1.02435 \\
\hline
\end{tabular}

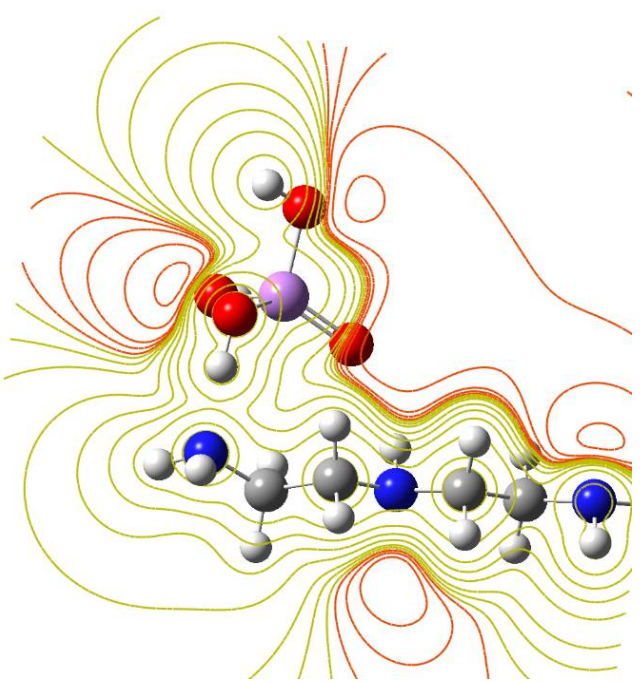

Figure 11. Contour mapping of As-TEPA-GTS. 
Table 6. NBO charge distribution of TEPA-GTS, $\mathrm{H}_{3} \mathrm{AsO}_{4}$ and As-TEPA-GTS.

\begin{tabular}{cccc}
\hline \multicolumn{2}{c}{ TEPA-GTS and $\mathrm{H}_{\mathbf{3}}$ ASO $_{4}$} & \multicolumn{2}{c}{ As-TEPA-GTS } \\
\hline $\mathrm{N} 1$ & -0.83850 & $\mathrm{~N} 1$ & -0.85379 \\
$\mathrm{H} 2$ & 0.33584 & $\mathrm{H} 2$ & 0.36266 \\
$\mathrm{H} \mathrm{3}$ & 0.34372 & $\mathrm{H} \mathrm{3}$ & 0.36837 \\
$\mathrm{As} 4$ & As 4 & 2.74799 \\
O 5 & 2.72387 & $\mathrm{O} \mathrm{5}$ & -1.09851 \\
H 6 & -1.03976 & $\mathrm{H} 6$ & 0.50843 \\
\hline
\end{tabular}

\section{Conclusions}

A new amino-functional adsorbent was prepared by copper-assisted chemical etching of kerf loss silicon waste, and shows effective removal of $\mathrm{As}(\mathrm{V})$ from aqueous solution. The TEPA-GTS-NPSi adsorbent can quickly reach adsorption equilibrium after $30 \mathrm{~min}$ and the maximum adsorption capacity of $\mathrm{As}(\mathrm{V})$ is $13.2 \mathrm{mg} / \mathrm{g}$ at room temperature. The adsorption kinetics could be well described with the pseudo-second-order kinetic model, which indicates the adsorption process was controlled by chemical interactions. The adsorption isotherms could be well described with the Langmuir isotherms model, which revealed the adsorption process was mono-layer adsorption. TEPA-GTS-NPSi could be regenerated with $1 \mathrm{~mol} / \mathrm{L} \mathrm{HCl}$ washing, which resulted in a low adsorption capacity attenuation after five cycles. The XPS and DFT analysis showed that the mechanism of As $(\mathrm{V})$ removal by TEPA-GTS-NPSi is mainly due to the strong hydrogen bonding between the $-\mathrm{NH}_{2}$ group and arsenic species. This work could provide novel insight into new absorbent fabrication and shows extremely practical significance to recycle kerf-loss silicon.

Supplementary Materials: The following are available online at https:/ /www.mdpi.com/article/10 .3390 / coatings11070850/s1, Figure S1: Silicon solar cell industry chain form solar grade silicon to solar module.

Author Contributions: Conceptualization, X.C. (Xiuhua Chen) and S.L.; methodology, K.F. and Y.L.; software, X.C. (Xiumin Chen); validation, Z.Y., Z.M. and K.F.; formal analysis, Z.M. and K.F.; investigation, Z.Y.; resources, J.L.; data curation, T.W.; writing—original draft preparation, Y.L.; writing-review and editing, S.L., K.F. and X.C. (Xiuhua Chen); visualization, J.L.; supervision, X.C. (Xiuhua Chen); project administration, R.C.; funding acquisition, X.C. (Xiuhua Chen) and W.M. All authors have read and agreed to the published version of the manuscript.

Funding: This research was funded by - the National Natural Science Foundation of China (Grant Nos. 51762043, 61764009, 51974143); National Key R\&D Program of China(No. 2018YFC1901801, No. 2018YFC1901805); Major Science and Technology Projects in Yunnan Province (No. 2019ZE007); Key Project of Yunnan Province Natural Science Fund (No. 2018FA027), Yunnan Ten Thousand Talents Plan Young \& Elite Talents Project; The Program for Innovative Research Team in University of Ministry of Education of China (No. IRT_17R48) and the 12th Graduate Research and Innovation Project of Yunnan University (No. 2020177).

Institutional Review Board Statement: Not applicable.

Informed Consent Statement: Not applicable.

Data Availability Statement: All data included in this study are available upon request by contact with the corresponding author.

Conflicts of Interest: The authors declare that they have no known competing financial interests or personal relationships that could have appeared to influence the work reported in this paper.

\section{References}

1. Srinivasan, S.; Kottam, V.K.R. Solar photovoltaic module production: Environmental footprint, management horizons and investor goodwill. Renew. Sustain. Energy Rev. 2018, 81, 874-882. [CrossRef]

2. Sreejith, K.; Sharma, A.K.; Kumbhar, S.; Kottantharayil, A.; Basu, P.K. An additive-free non-metallic energy efficient industrial texturization process for diamond wire sawn multicrystalline silicon wafers. Sol. Energy 2019, 184, 162-172. [CrossRef] 
3. Yang, Z.; Chen, X.; Li, S.; Ma, W.; Li, Y.; He, Z.; Hu, H.; Wang, T. Effective removal of Cd (II) from aqueous solution based on multifunctional nanoporous silicon derived from solar kerf loss waste. J. Hazard. Mater. 2019, 385, 121522. [CrossRef]

4. Yang, S.; Wei, K.; Ma, W.; Xie, K.; Wu, J.; Lei, Y. Kinetic mechanism of aluminum removal from diamond wire saw powder in $\mathrm{HCl}$ solution. J. Hazard. Mater. 2019, 368, 1-9. [CrossRef]

5. Yang, S.; Ma, W.; Wei, K.; Xie, K.; Wang, Z. Thermodynamic analysis and experimental verification for silicon recovery from the diamond wire saw silicon powder by vacuum carbothermal reduction. Sep. Purif. Technol. 2019, 228, 115754. [CrossRef]

6. Yang, S.; Wan, X.; Wei, K.; Ma, W.; Wang, Z. Dissolution and mineralization behavior of metallic impurity content in diamond wire saw silicon powder during acid leaching. J. Clean. Prod. 2020, 248, 119256. [CrossRef]

7. Wang, Y.-Y.; Chai, L.-Y.; Yang, W.-C. Arsenic Distribution and Pollution Characteristics in Arsenic Pollution Control in Nonferrous Metallurgy; Springer: Berlin/Heideberg, Germany, 2019; pp. 1-15.

8. Ganesan, N.; Bambino, K.; Boffetta, P.; Labgaa, I. Exploring the potential carcinogenic role of arsenic in gallbladder cancer. Eur. J. Cancer Prev. 2020, 29, 100-109. [CrossRef] [PubMed]

9. Aredes, S.; Klein, B.; Pawlik, M. The removal of arsenic from water using natural iron oxide minerals. J. Clean. Prod. 2013, 60, 71-76. [CrossRef]

10. Ahoranta, S.H.; Kokko, M.E.; Papirio, S.; Özkaya, B.; Puhakka, J.A. Arsenic removal from acidic solutions with biogenic ferric precipitates. J. Hazard. Mater. 2016, 306, 124-132. [CrossRef]

11. Kabay, N.; Ipek, İ.Y.; Yilmaz, P.K.; Samatya, S.; Bryjak, M.; Yoshizuka, K.; Tuncel, S.A.; Yükel, Ü.; Yüksel, M. Removal of Boron and Arsenic from Geothermal Water by Ion-Exchange in Geothermal Water Management; CRC Press: Boca Raton, FL, USA, 2018; pp. 135-155.

12. Mohora, E.; Rončević, S.; Agbaba, J.; Zrnić, K.; Tubić, A.; Adžemović, M.; Dalmacija, B. Effects of combined Fe-Al electrodes and groundwater temperature on arsenic removal by electrocoagulation. Environ. Prot. Eng. 2019, 45. [CrossRef]

13. Kumar, M.; RaoT, S.; Isloor, A.M.; Ibrahim, G.S.; Ismail, N.; Ismail, A.F.; Asiri, A.M. Use of cellulose acetate/polyphenylsulfone derivatives to fabricate ultrafiltration hollow fiber membranes for the removal of arsenic from drinking water. Int. J. Biol. Macromol. 2019, 129, 715-727. [CrossRef]

14. Elcik, H.; Celik, S.O.; Cakmakci, M.; Özkaya, B. Performance of nanofiltration and reverse osmosis membranes for arsenic removal from drinking water. Desalination Water Treat. 2016, 57, 20422-20429. [CrossRef]

15. Kazi, T.G.; Brahman, K.D.; Baig, J.A.; Afridi, H.I. A new efficient indigenous material for simultaneous removal of fluoride and inorganic arsenic species from groundwater. J. Hazard. Mater. 2018, 357, 159-167. [CrossRef]

16. Hao, L.; Zheng, T.; Jiang, J.; Zhang, G.; Wang, P. Removal of As (III) and As (V) from water using iron doped amino functionalized sawdust: Characterization, adsorptive performance and UF membrane separation. Chem. Eng. J. 2016, 292, 163-173. [CrossRef]

17. Karanac, M.; Đolić, M.; Veličković, Z.; Kapidžić, A.; Ivanovski, V.; Mitrić, M.; Marinković, A. Efficient multistep arsenate removal onto magnetite modified fly ash. J. Environ. Manag. 2018, 224, 263-276. [CrossRef] [PubMed]

18. Vojoudi, H.; Badiei, A.; Bahar, S.; Ziarani, G.M.; Faridbod, F.; Ganjali, M.R. Post-modification of nanoporous silica type SBA-15 by bis (3-triethoxysilylpropyl) tetrasulfide as an efficient adsorbent for arsenic removal. Powder Technol. 2017, 319, 271-278. [CrossRef]

19. Sherlala, A.; Raman, A.; Bello, M. Synthesis and characterization of magnetic graphene oxide for arsenic removal from aqueous solution. Environ. Technol. 2019, 40, 1508-1516. [CrossRef] [PubMed]

20. Kim, D.; Zuidema, J.M.; Kang, J.; Pan, Y.; Wu, L.; Warther, D.; Arkles, B.; Sailor, M.J. Facile surface modification of hydroxylated silicon nanostructures using heterocyclic silanes. J. Am. Chem. Soc. 2016, 138, 15106-15109. [CrossRef]

21. Xi, F.; Cui, H.; Zhang, Z.; Yang, Z.; Li, S.; Ma, W.; Wei, K.; Chen, Z.; Lei, Y.; Wu, J. Novel and efficient purification of silicon through ultrasonic-Cu catalyzed chemical leaching. Ultrason. Sonochem. 2019, 56, 474-480. [CrossRef] [PubMed]

22. Xi, F.; Li, S.; Ma, W.; He, Z.; Geng, C.; Chen, Z.; Wei, K.; Lei, Y.; Xie, K. Simple and high-effective purification of metallurgical-grade silicon through Cu-catalyzed chemical leaching. JOM 2018, 70, 2041-2047. [CrossRef]

23. Jarzabek, D.M.; Siewert, D.; Fabianowski, W.; Schift, H.; Rymuza, Z.; Jung, T. Influence of alkali ions on tribological properties of silicon surface. Tribol. Lett. 2015, 60, 1-8. [CrossRef]

24. Wayner, D.D.M.; Wolkow, R.A. Organic modification of hydrogen terminated silicon surfaces. J. Chem. Soc. Perkin Trans. 2 2002, 2, 23-34.

25. Zhang, D.; Gan, Y. Recent progress on critical cleaning of sapphire single-crystal substrates: A mini-review. Recent Pat. Chem. Eng. 2013, 6, 161-166. [CrossRef]

26. Gupta, V.; Moradi, O.; Tyagi, I.; Agarwal, S.; Sadegh, H.; Shahryari-Ghoshekandi, R.; Makhlouf, A.; Goodarzi, M.; Garshasbi, A. Study on the removal of heavy metal ions from industry waste by carbon nanotubes: Effect of the surface modification: A review. Crit. Rev. Environ. Sci. Technol. 2016, 46, 93-118. [CrossRef]

27. del Hierro, I.; Pérez, Y.; Fajardo, M. Supported choline hydroxide (ionic liquid) on mesoporous silica as heterogeneous catalyst for Knoevenagel condensation reactions. Microporous Mesoporous Mater. 2018, 263, 173-180. [CrossRef]

28. Pan, Q.; Wang, B.; Chen, Z.; Zhao, J. Reinforcement and antioxidation effects of antioxidant functionalized silica in styrenebutadiene rubber. Mater. Des. 2013, 50, 558-565. [CrossRef]

29. Fan, H.-T.; Sun, T.; Xu, H.-B.; Yang, Y.-J.; Tang, Q.; Sun, Y. Removal of arsenic (V) from aqueous solutions using 3-[2-(2aminoethylamino) ethylamino] propyl-trimethoxysilane functionalized silica gel adsorbent. Desalination 2011, 278, 238-243. [CrossRef] 
30. Behjati, M.; Baghdadi, M.; Karbassi, A. Removal of mercury from contaminated saline wasters using dithiocarbamate functionalized-magnetic nanocomposite. J. Environ. Manag. 2018, 213, 66-78. [CrossRef]

31. Xiong, C.; Wang, S.; Zhang, L.; Li, Y.; Srinivasakannan, C.; Peng, J. Preparation and application of phosphinic acid functionalized nanosilica for the effective removal of mercury (II) in aqueous solutions. J. Sol. Gel. Sci. Technol. 2018, 87, 442-454. [CrossRef]

32. Ananpattarachai, J.; Kajitvichyanukul, P. Enhancement of chromium removal efficiency on adsorption and photocatalytic reduction using a bio-catalyst, titania-impregnated chitosan/xylan hybrid film. J. Clean. Prod. 2016, 130, 126-136. [CrossRef]

33. Wu, L.-K.; Wu, H.; Zhang, H.-B.; Cao, H.-Z.; Hou, G.-Y.; Tang, Y.-P.; Zheng, G.-Q. Graphene oxide $/ \mathrm{CuFe}_{2} \mathrm{O}_{4}$ foam as an efficient absorbent for arsenic removal from water. Chem. Eng. J. 2018, 334, 1808-1819. [CrossRef]

34. Lee, J.; Kim, J.-H.; Choi, K.; Kim, H.-G.; Park, J.-A.; Cho, S.-H.; Hong, S.W.; Lee, J.-H.; Lee, J.H.; Lee, S. Investigation of the mechanism of chromium removal in (3-aminopropyl) trimethoxysilane functionalized mesoporous silica. Sci. Rep. 2018, 8, 1-11. [CrossRef]

35. Liu, C.-H.; Chuang, Y.-H.; Chen, T.-Y.; Tian, Y.; Li, H.; Wang, M.-K.; Zhang, W. Mechanism of arsenic adsorption on magnetite nanoparticles from water: Thermodynamic and spectroscopic studies. Environ. Sci. Technol. 2015, 49, 7726-7734. [CrossRef]

36. Setyono, D.; Valiyaveettil, S. Chemically modified sawdust as renewable adsorbent for arsenic removal from water. ACS Sustain. Chem. Eng. 2014, 2, 2722-2729. [CrossRef]

37. Zhu, N.; Yan, T.; Qiao, J.; Cao, H. Adsorption of arsenic, phosphorus and chromium by bismuth impregnated biochar: Adsorption mechanism and depleted adsorbent utilization. Chemosphere 2016, 164, 32-40. [CrossRef]

38. Shokri, E.; Yegani, R.; Akbarzadeh, A. Novel adsorptive mixed matrix membranes by embedding modified montmorillonite with arginine amino acid into polysulfones for As (V) removal. Appl. Clay Sci. 2017, 144, 141-149. [CrossRef]

39. Li, L.; Wu, C.; Wang, Z.; Zhao, L.; Li, Z.; Sun, C.; Sun, T. Density functional theory (DFT) and natural bond orbital (NBO) study of vibrational spectra and intramolecular hydrogen bond interaction of l-ornithine-1-aspartate. Spectrochim. Acta Part A Mol. Biomol. Spectrosc. 2015, 136, 338-346. [CrossRef]

40. Muthuraja, P.; Dhandapani, M. Quantum chemical calculations, physico-chemical characterizations and crystal structural analysis of a new organic-hydrogen bond networked crystal, 2-aminothiazolium benzilate. J. Mol. Struct. 2019, 1197, $19-33$. 